Session 1625

\title{
Tool Design Courseware for Modular Fixturing Applications in Manufacturing Engineering Technology
}

\author{
Veekit O'Charoen, Teresa J.K. Hall \\ Western Washington University / South Dakota State University
}

\section{Introduction}

Tool design encompasses a variety of applied technologies, engineering knowledge, and technical skills in the modern manufacturing engineering environment. The successful tool designer must be able to incorporate computer-assisted design (CAD), computer-aided manufacturing (CAM), traditional machining processes, ergonomics, and applied science to solve tooling applications problems and create new tooling designs. Overlay engineering and design skill with the ability to apply cost analysis and basic business operations management and it becomes apparent that it is no small task to be a tool design engineer.

There has also been an evolution in modern manufacturing operations where modular fixturing has become a key application in cellular and demand flow systems. ${ }^{1}$ The appeal of modular fixturing to manufacturing management is it's relatively low cost when considering all factors which included interchangeability and standardization across product lines. Purchasing modular fixturing elements, when available and appropriate, decreases the need for skilled toolmakers to fabricate one-of-a-kind fixtures, allows recycling of standard components after the production run is complete, and lowers indirect costs of maintaining expense stores inventories. Depending on the application, modular fixturing has great potential for cost savings in jigs and fixtures for automated systems.

At the same time fundamental changes were occurring in the manufacturing setting, there have been few corresponding computer-based teaching tools in the tool design applications area. Traditionally, the instructor used lecture on the topic accentuated by videos and/or CAD graphics of the tooling elements. If students were fortunate, they are given physical components to pass around, catalogs to peruse, and a tour of local manufacturing operations with processes of interest in close proximity for observation. The wide variety of tooling and fixtures are difficult to cover within a single semester, especially if consideration of related topics on gaging, cutting tools, and geometric dimensioning and tolerancing are included. ${ }^{2}$

The need for interactive teaching tools for discreet technical fields such as modular fixturing in tool design applications is indicated and as a result, the primary author has created ToolTRAIN ${ }^{\odot}$ courseware as a solution to this problem. 


\section{ToolTRAIN $^{\odot}$ Plus}

The original concept to develop the courseware evolved from an interest in courseware applications for manufacturing technology curriculum. ${ }^{3}$ There were no courseware tools found for tooling and fixture design applications available for educators and the project to fill this void was initiated. ToolTRAIN ${ }^{\mathcal{C}}$ Plus is the most recent version of this courseware. The following table shows the mechanism software behind ToolTRAIN ${ }^{\odot}$.

\begin{tabular}{|l|l|}
\hline Software Package & Function \\
\hline Macromedia Authorware ${ }^{\circledR} 6$ & Authoring System \\
Pro/ENGINEER ${ }^{\circledR}$ Wildfire $^{\mathrm{TM}}$ & Solid Modeling \\
3D Studio MAX ${ }^{\circledR}$ R3 & Animation \\
Adobe Photoshop ${ }^{\circledR} 5.5$ & Digital Illustration \\
Adobe Premiere ${ }^{\circledR} 5.1$ & Video Editing \\
Goldwave ${ }^{\circledR} 4.02$ & Sound Editing \\
\hline
\end{tabular}

Table 1. Software packages and their function as sub-elements for ToolTRAIN ${ }^{\odot}$.

\footnotetext{
Authorware $^{\circledR} 6$

Authorware $^{\circledR}$ is a very comprehensive authoring software package intended for users with full commitment to creating multimedia-tutoring systems. Authorware's basic operating style allows the user to create an interactive production by drawing flowchart like diagrams whose interconnected icons control how the project plays back (see Figure 1). Some icons cause the project to branch to different areas depending on user choices. Users can incorporate text, graphics, sound, animation and video from a number of complementary programs. With these capabilities, Authorware ${ }^{\circledR} 6$ was the primary software architecture and mechanism behind ToolTRAIN $^{\odot}$.
} 


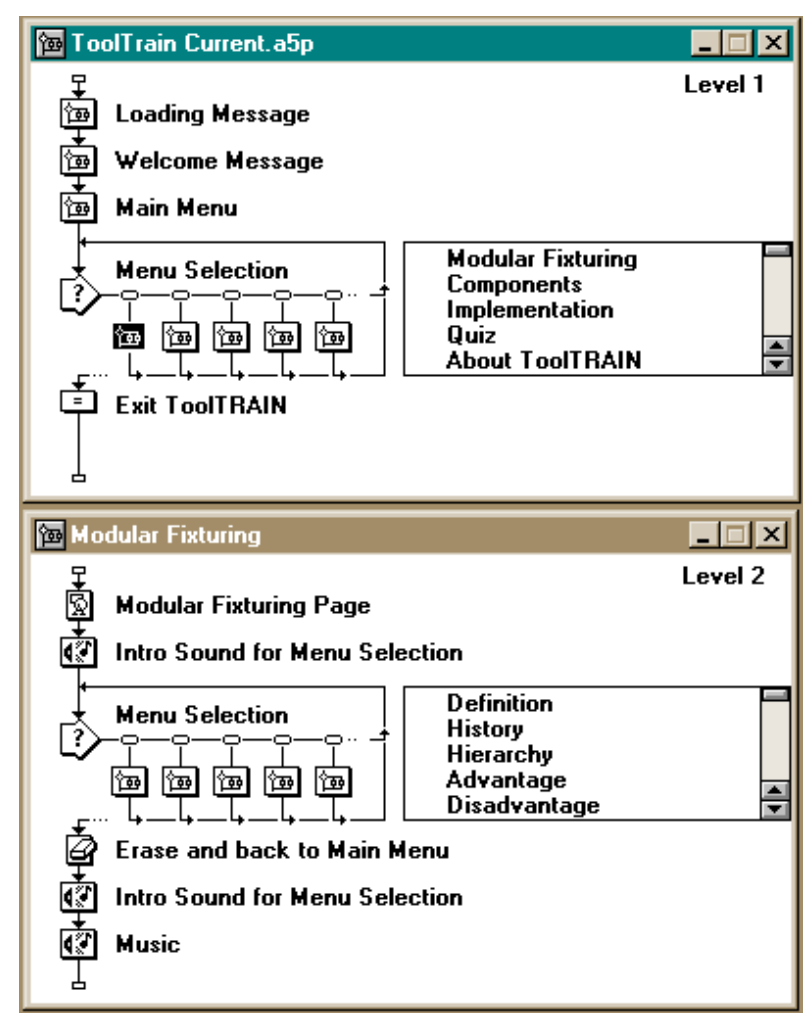

Figure 1. Interconnected icon control in Authorware ${ }^{\circledR,}$ s environment.

\section{Pro/ENGINEER ${ }^{\circledR}$ Wildfire $^{\mathrm{TM}}$}

The latest mechanical CAD offering from PTC (Parametric Technology Corp), represents the twenty-fourth major release of the software that incorporates several hundred improvements and its user interface is drastically update. ${ }^{4}$ A fully parametric based solid modeling software product, Pro/ENGINEER ${ }^{\circledR}$ uses feature-based modeling to create a part. This means the designer creates all the features that make up that part. Typically, the designer begins with a base feature, which is a solid object roughly the shape of the part he/she wants to create. Then, the designer can add features (cuts, slots, holes, chamfers, and other features) that shape the base object into the part. With Pro/ENGINEER ${ }^{\circledR}$, it is possible to examine the final part in a number of ways including wireframe, hidden line, and shaded versions. The primary author utilized this software to create all of modular fixturing components that are shown in ToolTRAIN ${ }^{\complement}$. Pro/ENGINEER ${ }^{\circledR}$ Wildfire also provides different formats for exporting a file to the different application software packages.

\section{$\underline{\text { 3D Studio } \mathrm{MAX}^{\circledR} \mathrm{R} 3}$}

This was the professional 3D modeling, animation and rendering software for creating visual effects, character animation and next generation game development. 3D Studio MAX ${ }^{\circledR}$ R3 delivers a fully collaborative 3D environment and new high-speed interactive rendering. With completely customizable and extensible architecture, it allows for absolute artistic freedom. 3D Studio MAX $^{\circledR}$ R3 supports the largest third-party integrated application developer community of 
any 3D application. In ToolTRAIN ${ }^{\odot}, 3 \mathrm{D}$ Studio $\mathrm{MAX}^{\circledR} \mathrm{R} 3$ was used to create an animation of several modular fixturing systems. All of the solid models (modular fixturing components) were imported from Pro/ENGINEER with a sterolithography (STL) format. This allows all data to be transmitted into different type of 3D solid modeling software.

\section{Adobe Photoshop ${ }^{\circledR} 5.5$}

This software combines powerful image-editing capabilities with a useful interface. It is easy for users to utilize. Several digital illustrations in ToolTRAIN ${ }^{\circledR}$ benefit from Photoshop's features, such as modes, options, and special layers. Most tools have customization settings to determine how quickly the system can perform and what aspects of the image system modify.

\section{Adobe Premiere $^{\circledR} 5.1$}

This software is a great tool to edit video. Adobe Premiere ${ }^{\circledR} 5.1$ remains the power user's video editor of choice. This product is a traditional editor in which separate windows provide access to a multitrack timeline, previews, transitions, trimming functions, and a clip library. Tools such as ripple and rolling edits, multiple-track selection, and the jog, shuttle, and play commands in the clip window make it possible to edit large amounts of image on film very quickly. The researcher took advantage of these features to edit several video clips that appear in ToolTRAIN $^{\circledR}$.

Goldwave ${ }^{\circledR} 4.02$.

This is a comprehensive digital audio editor. It contains many great features such as play, edit, mix, and analyze audio. Goldwave ${ }^{\circledR} 4.02$ was used to edit all of digital audio parts in ToolTRAIN $^{\circledR}$ development process.

\section{ToolTRAIN $^{\circledR}$ The instruction system}

There are four main units in the instruction system of the courseware: they are (1) Modular Fixturing; (2) Components; (3) Implementation; and (4) Quiz. The lessons are delivered in a step-by-step format that allows students to repeatedly review the modular tooling concepts in each unit until they have achieved understanding. The sublevels of the courseware are intuitive and navigation is straightforward. A hierarchy diagram of tutorial content is shown in Figure 2. Figure 3 shows the main screen of ToolTRAIN ${ }^{\circledR}$ Plus.

\section{$\underline{\text { Introduction unit }}$}

The introduction unit provides a definition, an applications perspective, hierarchy of related workholders or other tooling, and covers the advantages and disadvantages of using modular fixturing. The introduction unit also includes a video clip from a tool design professor who shares an alternative idea for a modular fixturing concept. The unit incorporates graphics, written definitions, animated sequences that show how components fit together in a sample application, and 2D isometric drawings that give the student insight into appropriate drawing layout. 


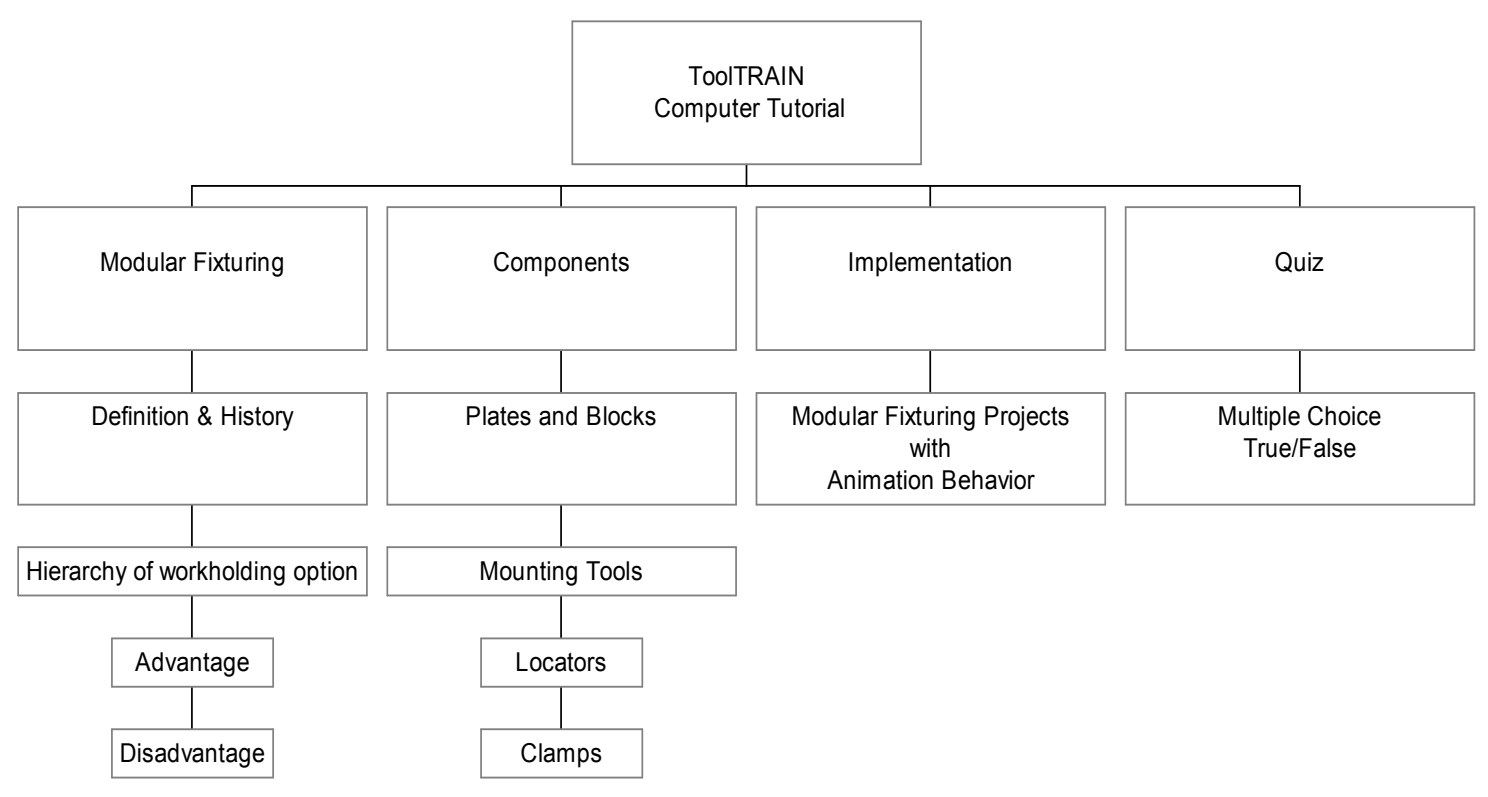

Figure 2. Hierarchy for the tutorial content.

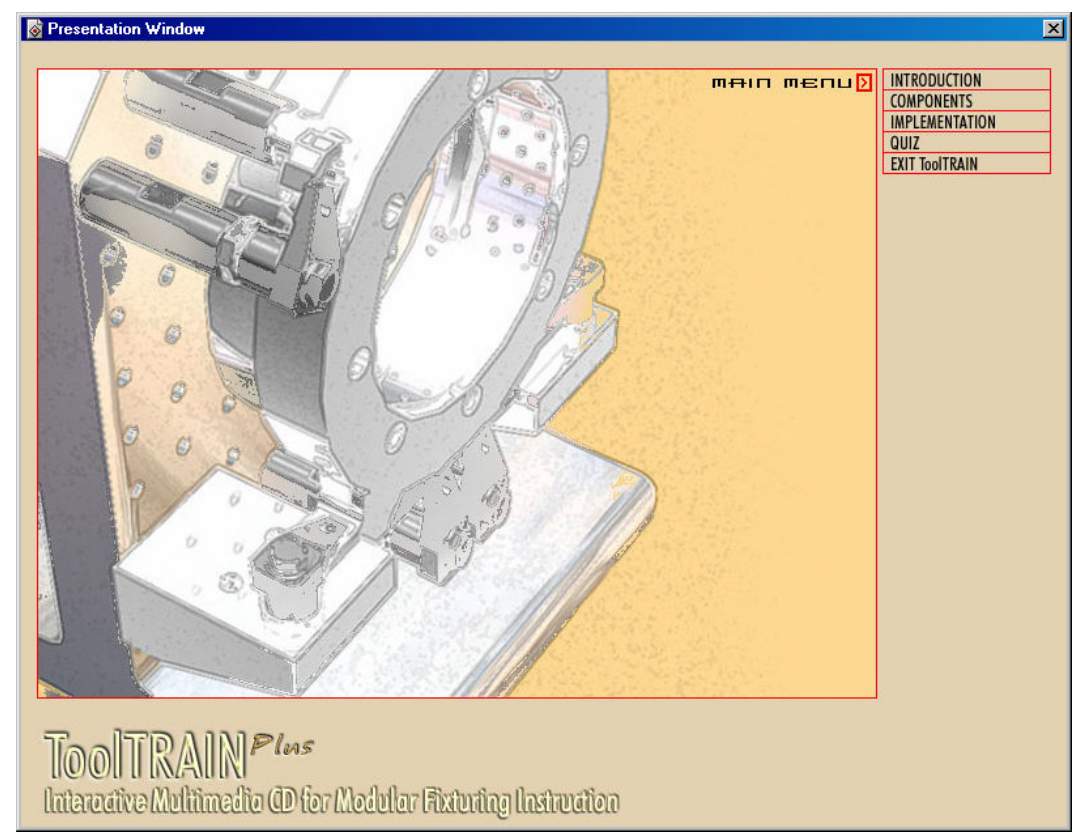

Figure 3. Introduction unit - main screen.

Proceedings of the 2004 American Society for Engineering Education Annual Conference \& Exposition Copyright $(\mathrm{C}) 2004$, American Society for Engineering Education 


\section{Component unit}

The components unit presents the fundamentals of modular fixturing components. Four main basic components of modular fixturing are introduced: (1) tooling plates and blocks; (2) mounting tools; (3) locators; and (4) clamps. Figure 4 shows an example screen of the component unit - a locator. For novices to tooling nomenclature and technology, the component units are especially valuable as the subtle differences between styles and correct application are critical to well-designed production fixturing. Over time, new components will be added as graphic files are developed.

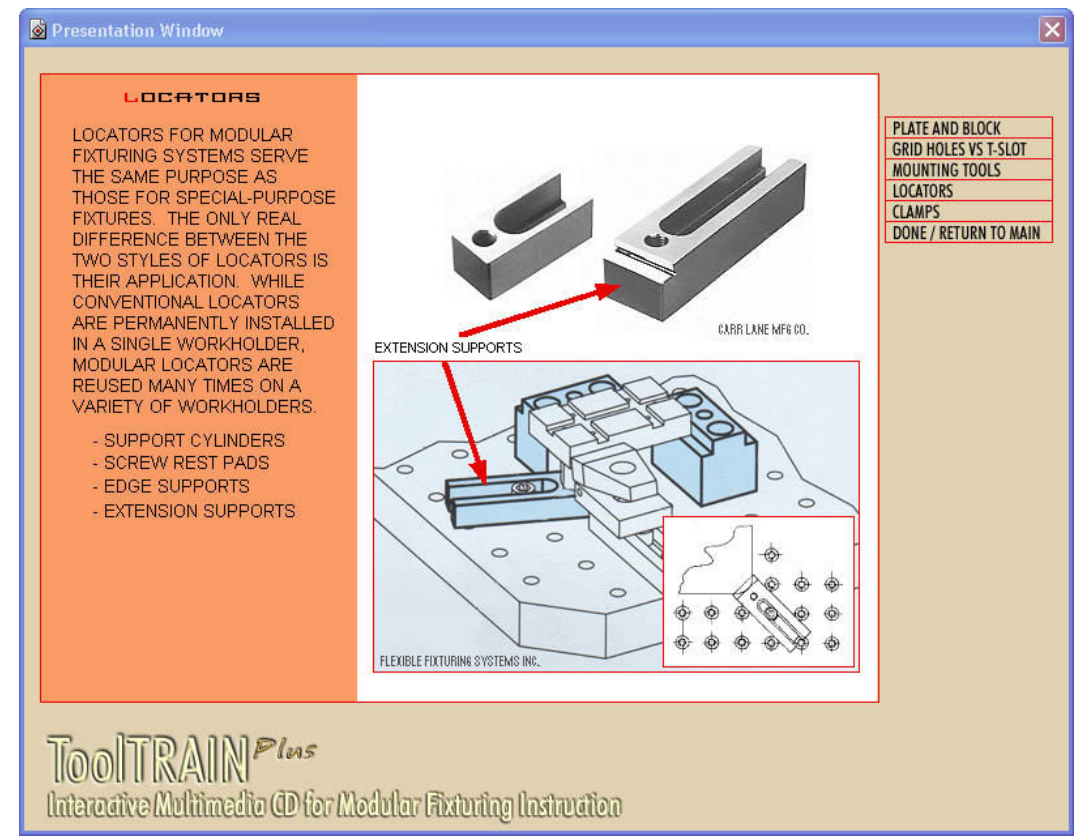

Figure 4. Component unit - locator.

\section{Implementation unit}

There are three main steps in the Computer-Aided Fixture Design (CAFD) process: setup planning, fixture planning, and fixture configuration design. ${ }^{5}$ The objective of setup planning is to determine the number of different setups needed and the orientation of workpiece and the machining surfaces in each setup. Fixture planning is used to determine the locating, supporting, and clamping points on a workpiece surface. Lastly, the objective of fixture configuration is to select fixture elements and place them into a final configuration in order to locate and clamp the workpiece. The intent of implementation unit in ToolTRAIN ${ }^{\mathcal{O}}$ is to introduce a basic concept of modular fixturing components and samples of fixture configuration designs, therefore setup planning and fixture planning are not currently addressed in ToolTRAIN ${ }^{\circ}$ courseware. The implementation unit in ToolTRAIN ${ }^{\mathcal{O}}$ contains five projects based on different part geometry. The use of animation series in the implementation unit is very helpful for student learning especially when several modular fixture components are moved into a final configuration. Figures 5 and 6 show a process of instruction and example screen of the implementation unit respectively. 


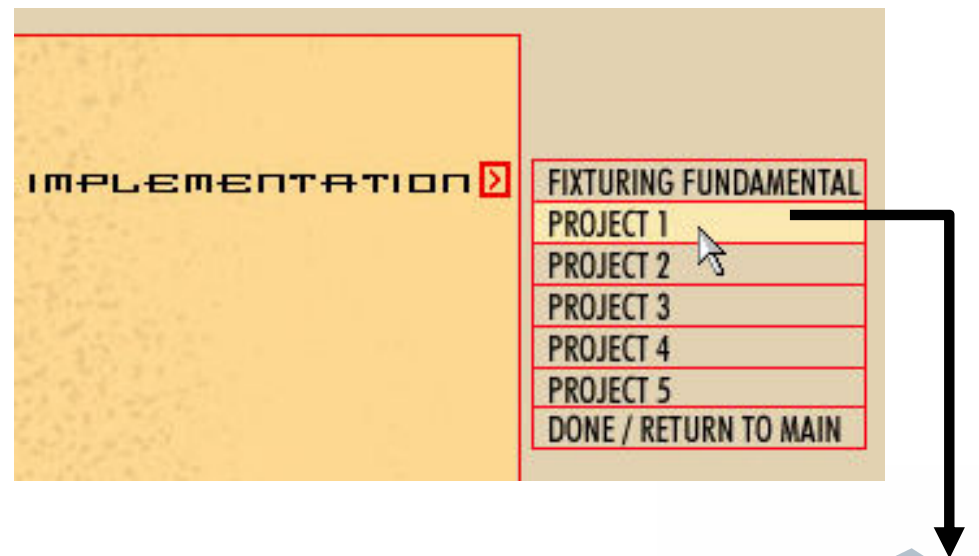

Part geometry is introduced

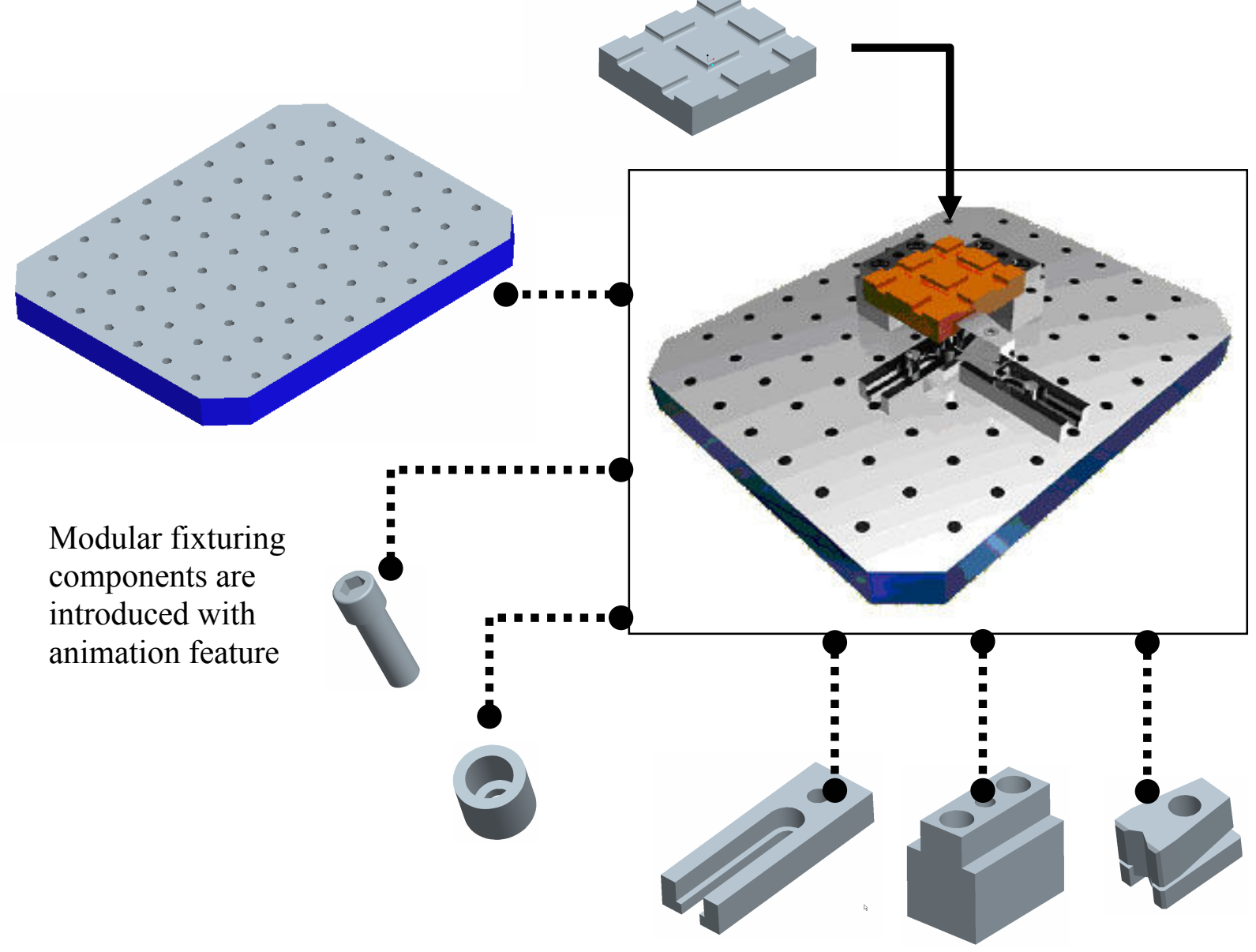

Figure 5. Example of implementation project (modular fixturing configuration) in ToolTRAIN ${ }^{\odot}$ All components were modeled and rendered by the Veekit $O$ 'Charoen and Brian Perry, original fixture design concept from Halder Norn+Technik, Flexible Fixturing System Inc., East Granby, CT 06026-0787. 


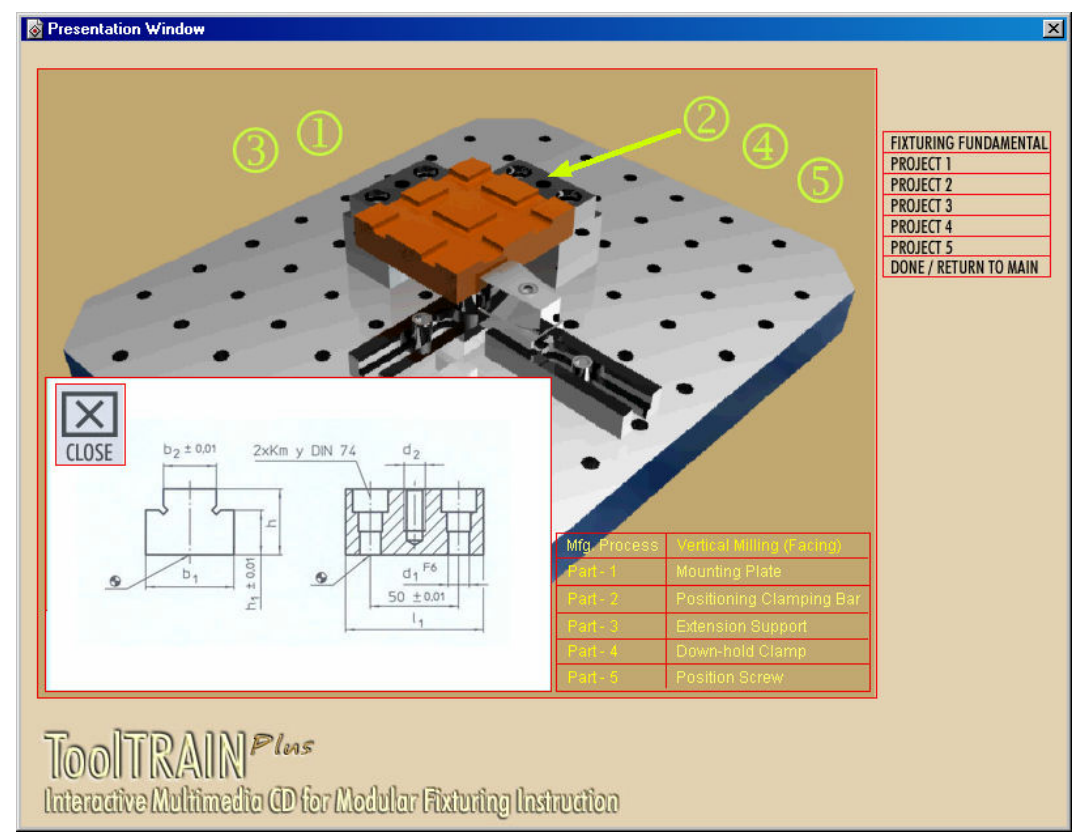

Figure 6. Implementation unit.

Quiz unit

The remaining teaching unit in ToolTRAIN ${ }^{\odot}$ is a quiz where students can test their knowledge multiple choice and true/false questions. Based on material presented in the modular fixturing definitions, components, or the implementation unit, students must review the corresponding drawing to the question and submit their response. The following Figure 7 shows the sample of the quiz unit.

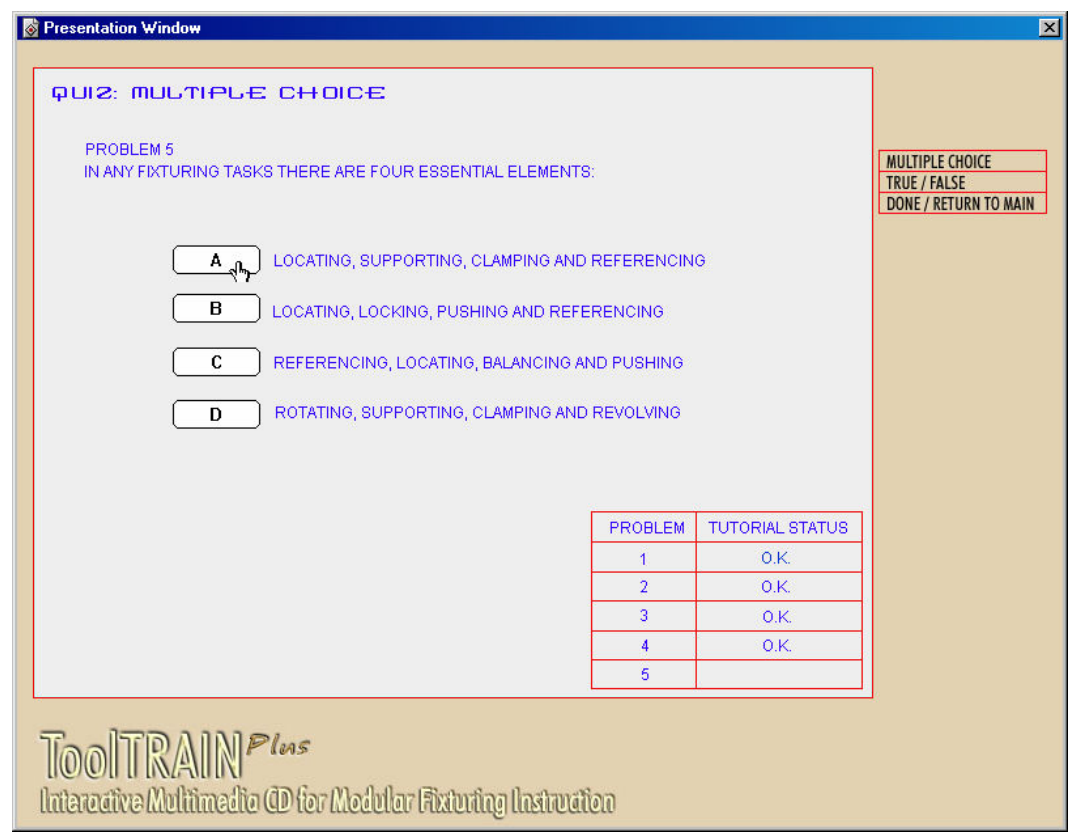

Figure 7. Quiz unit.

Proceedings of the 2004 American Society for Engineering Education Annual Conference \& Exposition Copyright $(\mathrm{C}) 2004$, American Society for Engineering Education 


\section{ToolTRAIN $^{\odot}$ Release 4 VS ToolTRAIN ${ }^{\complement}$ Plus}

The original version of ToolTRAIN ${ }^{\odot}$ was developed at the Department of Industrial Technology, University of Northern Iowa in 2000. After several trial versions, ToolTRAIN ${ }^{\complement}$ Release 4 was an official release to test with a group of student in the department. Although the mechanism software behind the original version of ToolTRAIN ${ }^{\odot}$ is fundamentally unchanged (see Table 1), the goal of ToolTRAIN ${ }^{\circledR}$ Plus was to add motion visualization capabilities. Enhancements in these two areas should improve student understanding and knowledge retention in addition to improvement in usability of the courseware. The user interface of ToolTRAIN ${ }^{\complement}$ is built on the concept of menu-based interaction. Menu-based interaction is the user interface that presents the user with a display of options, and the selection of an option may generate a further set of options. ${ }^{6}$ The architecture of this user interface is comprehensive and linked to the submenu in each unit of tutorial (Figure 8). The functions provided by the user interface (menu picks) show up to the right corner of each page, with commands arranged vertically.

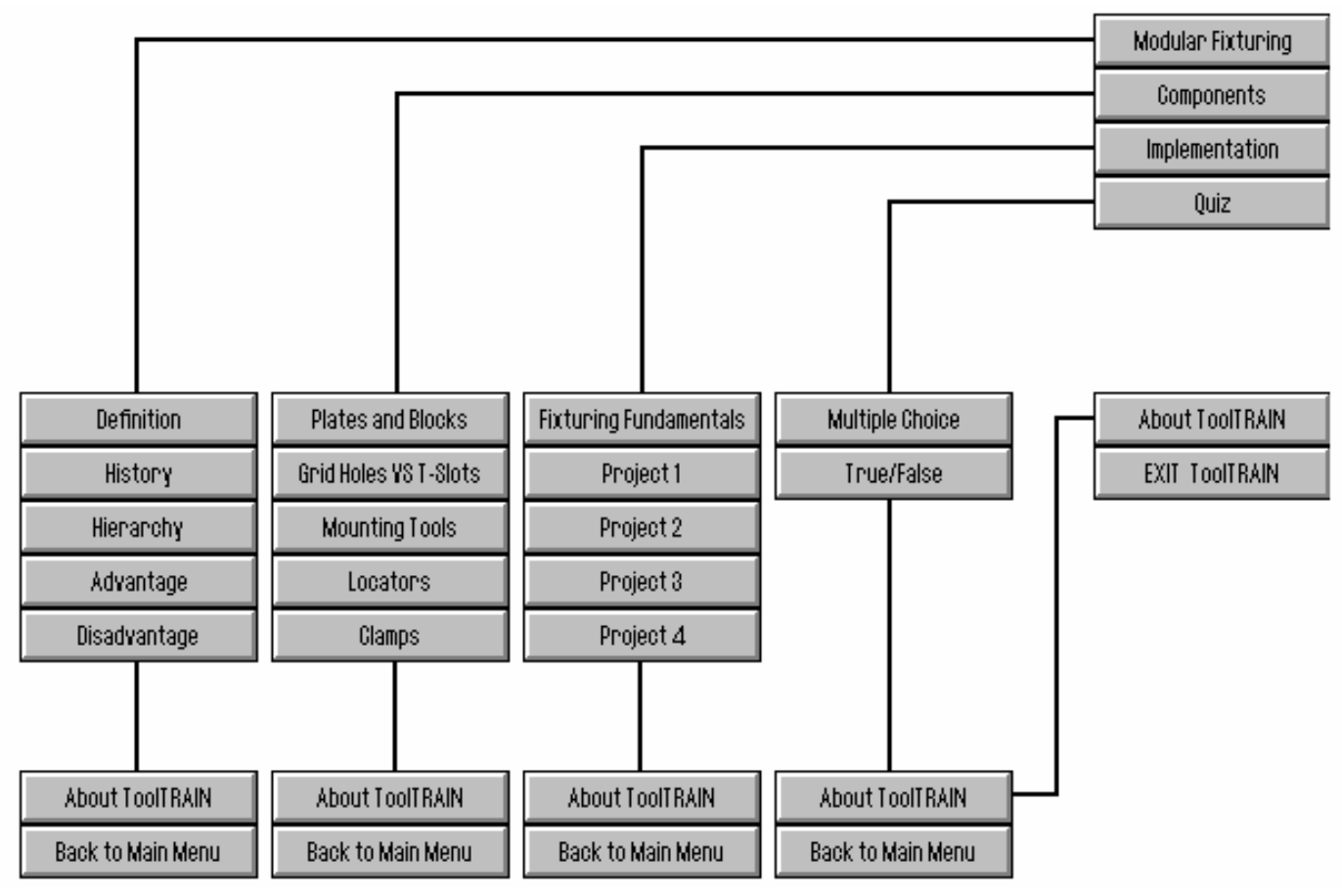

Figure 8 Architecture of ToolTRAIN ${ }^{\circledR}$, s user interface.

With improvements in ToolTRAIN ${ }^{\complement}$ Plus, as users move the mouse pointer up and down within command menus, a different color under pointer appears at the same time. The different color ensures that users selected the right choices. This prevents the user from issuing an inappropriate or unavailable command. The navigated menu informs where the user is in the system. The subscreen will appear after users picked the menu interface prior to the tutorial begin the training process (see Table 2). 


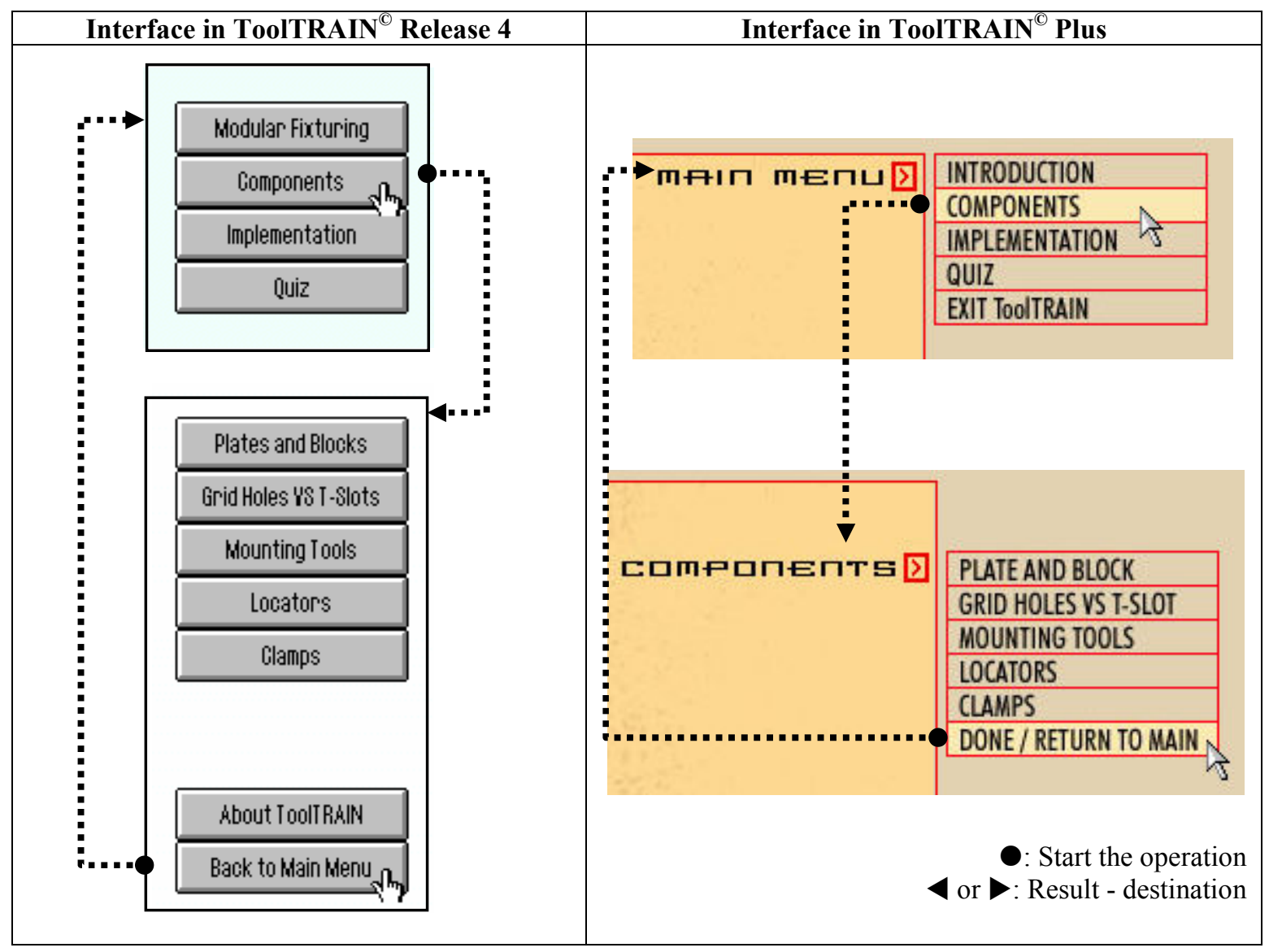

Table 2. ToolTRAIN ${ }^{\odot}$ releases 4 VS Plus user interface.

\section{Assessment/Classroom testing}

ToolTRAIN $^{\odot}$ courseware has been subjected to extensive testing on undergraduate students in manufacturing technology tooling courses. Corrections and additional training units have been performed as a result. ${ }^{7}$ A quasi-experimental design of the non-equivalent control group was utilized for the previous study with ToolTRAIN ${ }^{\odot}$ Release 4 . The population of the study was comprised of the students who enrolled in the Manufacturing Technology, Electro Mechanical System, General Industry \& Technology and Technology Education programs at the University of Northern Iowa during the spring of 2000 semester.

The samples from the population for the study were 15 students enrolled in the experimental group and another 15 students enrolled in the control group (due to a limited number of students in Tool Design class during spring of 2000 semester, 7 volunteer students were added to the control group). Although some authorities suggested that 30 subjects per group should be considered minimum, Gay $^{8}$ recommends a minimum of 15 subjects per group for experimental studies. A priori power estimation is complicated in situation like this, where little previous research is available to permit estimation of effect magnitude. However, after some deliberation (personal communication with Dr. Andrew R. Gilpin, May, 2001) it was presumed that the use 
of a repeated measurers design would allow detection of moderate effects with 15 participants in each group (in fact, the significant results reported suggest that this was a reasonable assumption). The three hypotheses predict that subjects in the experimental group should show change scores (posttest - pretest) which are at least as large as those obtained by subjects in the lecture group. This study was designed to test the following null hypotheses.

- Major null hypothesis. There is no significant difference between the general performance on test scores of students who used the computer tutorial and those who experienced traditional teaching methods.

- Sub-null hypothesis 1.

There is no significant difference between the performance on knowledge test scores of basic concepts and principles of modular fixturing of students who used the computer tutorial and those who experienced traditional teaching methods.

- Sub-null hypothesis 2.

There is no significant difference between the performance on knowledge test scores of modular fixturing components of students who used the computer tutorial and those who experienced traditional teaching methods.

- Sub-null hypothesis 3.

There is no significant difference between the performance on knowledge test scores of modular fixturing implementation of students who used the computer tutorial and those who experienced traditional teaching methods.

Three hours were used to teach the control group by lecture. The experimental group was expected to utilize ToolTRAIN ${ }^{\odot}$ for three hours. The posttest was administered to measure knowledge gain of modular fixturing design concepts after the instruction. To test each hypothesis, a separate independent group's t-test was computed comparing the change scores obtained by the computer tutorial group with those obtained by the lecture group. For each test, the null hypothesis was that there is no difference in the means of the two groups; the statistical alternative is that the means of the two groups are different in which case the direction of the difference was examined to determine which group showed more improvement.

Table 3 shows the mean and standard deviation on the change in scores based on four areas of knowledge. The knowledge examination consisted of 25 multiple-choice items. Seven items were developed to measure knowledge of basic concepts and principles of modular fixturing theories; eight items were developed to measure modular fixturing component knowledge; and ten items were developed to measure knowledge of modular fixturing implementation. The content of the posttest was the same as that of the pretest except that the questions were reordered. 


\begin{tabular}{|l|c|c|c|c|c|c|}
\hline \multirow{2}{*}{ Areas } & \multicolumn{3}{|c|}{ Control } & \multicolumn{3}{c|}{ Experimental } \\
\cline { 2 - 7 } & M & SD & n & M & SD & n \\
\hline $\begin{array}{l}\text { Basic Concept - } \\
\text { Introduction }\end{array}$ & 0.60 & 1.18 & 15 & 2.27 & 1.10 & 15 \\
\hline Components & 1.53 & 2.29 & 15 & 3.67 & 2.61 & 15 \\
\hline Implementation & 0.33 & 1.72 & 15 & 2.27 & 1.58 & 15 \\
\hline Full Scale & 2.47 & 2.47 & 15 & 8.20 & 3.59 & 15 \\
\hline
\end{tabular}

Table 3. Mean and standard deviations on the difference in score (change in score) based on four areas of knowledge.

For the basic concepts and principles of modular fixturing scale, as predicted, there were significant differences between group means, $t(28)=-3.996, p<0.001$ with the experimental group improving more. For the modular fixturing components scale, as predicted, there were significant differences between group means, $\mathrm{t}(28)=-2.378, \mathrm{p}<0.05$, with the greater change in the experimental group. For the modular fixturing implementation scale, the change scores also showed that there were significant differences between group means, $\mathrm{t}(28)=-3.208, \mathrm{p}<0.05$, again favoring the computer (experimental) group. Finally, for general performance on the test score (full scale), as predicted, the experimental group achieved significantly higher change in scores than the control group, $\mathrm{t}(28)=-5.093, \mathrm{p}<0.001$.

The questionnaire was provided to the experimental group (15 students) after they completed the experiment. The purpose was to obtain student opinions on the effectiveness of ToolTRAIN ${ }^{\odot}$ especially on the various components of the software. However, this evaluation procedure was not considered part of the primary experimental research. Some of the key questions that the students were asked, on a scale of 1 (very difficult) to 9 (very easy) and 1 (not helpful) to 9 (very helpful) were the following: was it difficult to remember the meaning of the commands to run the program? Was the layout of the screen helpful to understand how to use the program? Is it easy to go back and forth between screens of the program? Overall the results were very positive; the students found that software was not difficult to interact. The layout was clear and easy to go back and forth between screens.

Within the next academic year, ToolTRAIN ${ }^{\circledR}$ Plus will be used as a teaching tool at two more institutions in the United States. New units are being developed in conjunction with manufacturing tooling suppliers and additional quiz units are being written. Of note, ToolTRAIN $^{\mathbb{C}}$ Plus was developed to use with Windows 2000 and XP and was tested on both versions. The big factor in running this courseware is the speed of a CD-ROM drive; a readable 
speed of $20 \mathrm{X}$ or higher is ideal. At this time, there are no plans to develop a Mac OS-based version.

\section{Summary}

ToolTRAIN $^{\odot}$ is a courseware tool that can enhance traditional means of instruction in manufacturing tooling design courses. Some of the most dramatic are animation, audio, and interactive features. Similar controlled experiments with ToolTRAIN ${ }^{\circledR}$ Release 4 should be applied to ToolTRAIN ${ }^{\odot}$ Plus too in order to determine the overall effectiveness of multimedia instruction in a tool design course. ToolTRAIN ${ }^{\odot}$ Plus also can be used for more complex concepts of modular fixturing system and applications.

\section{References}

1. Nee, A. Y. C. and Kamar, A. S. (1991). A Framework for an object/rule-based automated fixture design system. Annals of CIRP, 147-151.

2. Society of Manufacturing Engineers (SME). (2003). Fundamentals of tool design. $\left(5^{\text {th }}\right.$ Edition). Dearborn, MI: Author.

3. O'Charoen, V. (2002). The effects of an interactive computerized multimedia tutorial on knowledge gain in modular fixturing design concepts (doctoral dissertation, University of Northern Iowa, 2002), Dissertation Abstracts International, DAI-B, 63(03), 1512.

4. Huxley, M. (2003). Pro/E Wildfire: Intuitive, scalable. CADalyst, 20(2), 30-36.

5. Rong, Y. and Bai, Y. (1997). Automated generation of fixture configuration design. Journal of Manufacturing Science and Engineering, 119, 208-219.

6. Newman, W. and Lamming, M. (1995). Interactive system design. New York:

Addison-Wesley Publishers.

7. O'Charoen, V., Kashef, A., and Gilpin. A. (2002). ToolTRAIN: An Interactive Computerized Multimedia Tutorial for Modular Fixturing Design Instruction. Proceedings of the $56^{\text {th }}$ Annual Mid-Year Conference of the Engineering Design Graphics Division (EDGD), ASEE, Berkeley, CA, 133-138.

8. Gay, L. (1996). Educational research: competencies for analysis and application. New Jersey: Prentice Hall.

\section{Acknowledgements}

The authors acknowledge and greatly appreciate the support given by the following companies:

- Carr Lane Manufacturing Company

- Flexible Fixturing Systems, Inc.

- Bluco Corporation

The authors also wish to recognize Mr. Brian Perry, Freelance Designer from Bellingham, WA for his excellent contributions in testing and checking the animation feature in ToolTRAIN ${ }^{\odot}$. For the long hours spent on this project, thank you! 


\section{Author Biographies}

VEEKIT O'CHAROEN, is an Assistant Professor of the Department of Engineering Technology at Western Washington University. He received his D.I.T. (Doctor of Industrial Technology) from University of Northern Iowa. His research interests include parametric solid modeling, animation behavior, visualization and interactive multimedia tutorials as it relates to tool design and engineering instruction.

TERESA J.K. HALL, Ph.D., CMfgE is Professor and Head of the Department of Engineering Technology and Management at South Dakota State University. Additionally, she is Director for the Polytechnic Center of Excellence within the College of Engineering at SDSU. Her research interests are in manufacturing resource deployment and curriculum development for technology related disciplines. 